\title{
NEW METHOD FOR CONTROLLABLE ACCELERATED AGING OF MARBLE: USE FOR TESTING OF CONSOLIDANTS
}

\author{
Enrico Sassoni ${ }^{1}$, Gabriela Graziani ${ }^{1}$, Elisa Franzoni ${ }^{1}$, George W. Scherer ${ }^{2}$ \\ ${ }^{1}$ Dept. Civil, Chemical, Environmental and Materials Engineering (DICAM), University of Bologna, Italy \\ ${ }^{2}$ Dept. Civil and Environmental Engineering (CEE), Princeton University, USA
}

\begin{abstract}
Research is needed on novel consolidants to restore weathered marble, because the available products exhibit limitations. To test new consolidants, samples with features similar to naturally weathered marble (i.e. near-surface damage) are recommended. We developed a novel method that produces decayed samples with a gradient in properties that can be tuned to any desired level, in terms of depth from the surface and decrease of dynamic elastic modulus. The idea is to produce near-surface damage by putting a marble sample in contact with a plate at a certain temperature for a certain time, calculated by a mathematical model. The model was used to predict the heating conditions to produce a certain decrease in dynamic elastic modulus in the first $1 \mathrm{~cm}$ from the surface, comparable to naturally weathered marble. Good confirmation of the model predictions was found experimentally. The suitability of using thermally "weathered" samples for testing consolidants was demonstrated in the case of a hydroxyapatite-based treatment. The mathematical model can be tailored to other lithotypes or ceramics, using the relevant property data.
\end{abstract}

\section{KEYWORDS}

Aging; Calcium phosphate; Consolidation; Cracks/cracking; Hydroxyapatite 
This is the peer reviewed version of the following article: Sassoni E., Graziani G., Franzoni E., Scherer G.W., New method for controllable accelerated aging of marble: use for testing of consolidants, Journal of the American Ceramic Society, which has been published in final form at DOI: 10.1111/jace.15522. This article may be used for non-commercial purposes in accordance with Wiley Terms and Conditions for Use of Self-Archived Versions.

\section{INTRODUCTION}

Marble is one of the most used materials in historic architecture and is still widely used to clad building façades. Unfortunately, marble is highly sensitive to thermal weathering, because it consists of calcite crystals that exhibit highly anisotropic thermal expansion ${ }^{1}$. Repeated heatingcooling cycles (such as day/night temperature variations) induce stress at grain boundaries and open new micro-cracks when the cohesion among grains is exceeded. This leads to the detachment of grains (the so-called "sugaring" phenomenon ${ }^{2}$ ), that may lead to the loss of several $\mathrm{mm}$ of material from the surface ${ }^{3-5}$, and to bowing of cladding slabs that may eventually fracture and fall down $n^{6-9}$. As a consequence of micro-crack formation, water can penetrate into marble and trigger additional weathering phenomena, such as dissolution at grain boundaries, freeze-thaw cycles, and salt crystallization cycles.

Several types of consolidants have been tested through the years, with the aim of bonding loose calcite grains and restoring mechanical properties ${ }^{10-12}$. However, research on consolidants is still in progress, because the products currently available in the market are not fully satisfactory, owing to problems such as inadequate penetration, coloration, and insufficient adhesion ${ }^{13}$. The development of new consolidants requires the use of suitable samples for testing the new materials. Naturally weathered samples are usually not available in sufficient quantity and with sufficiently uniform characteristics. Unweathered samples lack micro-cracks at grain boundaries, so that the ability of a consolidant to penetrate deeply into cracks and bond the crack surfaces cannot be assessed reliably ${ }^{14}$. Consequently, the use of artificially weathered samples is preferable. Several methods for artificial weathering of stone have been developed, including freeze-thaw cycles, salt crystallization cycles, acid attack, and mechanical pre-stress ${ }^{15-18}$. However, the suitability of these methods depends on the type of stone, its microstructure, and the type of weathering that one 
This is the peer reviewed version of the following article: Sassoni E., Graziani G., Franzoni E., Scherer G.W., New method for controllable accelerated aging of marble: use for testing of consolidants, Journal of the American Ceramic Society, which has been published in final form at DOI: 10.1111/iace.15522. This article may be used for non-commercial purposes in accordance with Wiley Terms and Conditions for Use of Self-Archived Versions.

intends to reproduce. In the case of carbonate stones, such as marble and limestone, in previous studies we showed that an effective way to induce new micro-cracks at grain boundaries, without causing contamination of the samples by salts or other residues, is to heat the stone to high temperature $\left(300-400{ }^{\circ} \mathrm{C}\right)$ in an oven, to exploit the anisotropic thermal behavior of calcite crystals $^{13,15,19}$. The newly formed micro-cracks lead to an increase in open porosity and water absorption and a decrease in cohesion resulting in a loss of stiffness and strength ${ }^{15,19}$. Notably, the damaging effect obtained by heating is sensibly greater for stones with low initial porosity, such as marble, because in porous stones the existing voids allow some deformation of calcite crystals without causing as much stress at the grain boundaries and consequently reduce formation of new micro-cracks ${ }^{19}$. However, this procedure has the limitation that so-obtained samples are uniformly weathered, i.e. they do not exhibit the gradient in properties that characterizes naturally weathered marble. For instance, the analysis of a marble element, which had been exposed outdoors for some 150 years, revealed strong decohesion of grains (measured by ultrasound) in the first $1 \mathrm{~cm}$ from the surface, with only a modest decay between 1 and $2 \mathrm{~cm}$ and no damage at greater depth ${ }^{20}$.

In this paper, we propose a novel method that provides decayed samples with a gradient in properties that can be tuned to any desired level, in terms of depth from the surface and magnitude of decrease in dynamic elastic modulus (which can be taken as indicative of mechanical damage, as detailed in the following). The method is based on the idea of producing near-surface damage by putting a marble sample in contact with a hot plate for a certain time. In this way, the damage is not uniform (unlike the case of samples heated in an oven), but the part closest to the plate experiences the greatest damage. It is true that such samples lack some of the features exhibited by naturally weathered marble, often also affected by additional weathering phenomena (such as dissolution at grain boundaries); however, inducing realistic micro-crack formation is regarded as the most important aspect, because thermal damage represents the first and often the most 
This is the peer reviewed version of the following article: Sassoni E., Graziani G., Franzoni E., Scherer G.W., New method for controllable accelerated aging of marble: use for testing of consolidants, Journal of the American Ceramic Society, which has been published in final form at DOI: 10.1111/jace.15522. This article may be used for non-commercial purposes in accordance with Wiley Terms and Conditions for Use of Self-Archived Versions.

important stage of marble deterioration in the field. The heating temperature and time necessary to reach a certain level of decay can be calculated by a mathematical model that takes into account how the thermal diffusivity $(k)$ and the dynamic elastic modulus $\left(E_{d}\right)$ of the lithotype change with temperature. The mathematical model is first presented and the experimental tests used to evaluate the temperature dependence of $k$ and $E_{d}$ are described. The model is then validated through an example of its application to produce damage to two different levels and the suitability of using soobtained samples for testing an innovative consolidant is finally illustrated.

\section{THEORETICAL MODELING}

For a marble sample put onto a hotplate at a certain initial temperature, the heat flow is governed by:

$$
\frac{\partial T}{\partial t}=\frac{\partial}{\partial x}\left(k[x, t] \frac{\partial T}{\partial x}\right)
$$

where $T$ is the temperature, $t$ is the time, $x$ is the distance from the heating plate and $k$ is the thermal diffusivity. If heat losses are prevented by insulating the top and the sides of the sample, the boundary conditions are zero flux at the top (insulated) surface and $T[0, t]$ measured at the surface in contact with the hotplate. In the present case, $k$ decreases as temperature increases, because micro-cracks that are formed at grain boundaries impede heat flow ${ }^{21}$. As a first approximation, the temperature dependence of $k$ was assumed to be exponential, based on the data reported in the literature for a different type of marble ${ }^{21}$ :

$$
k[x, t]=k_{1}+k_{2} \exp \left[\quad{ }_{k} T[x, t]\right]
$$

where $k_{1}, k_{2}$ and $\lambda_{\mathrm{k}}$ are constants. An analogous equation, 


$$
E_{d}=E_{0} \exp \left[{ }_{E} T\right]
$$

describes the temperature dependence of the dynamic elastic modulus, as shown in $\S 4.2$. However, it has been demonstrated experimentally that cooling does at least as much damage as heating ${ }^{22}$, so the simple dependence on $T$ in Eq. (2) is only a convenient approximation to describe heating cycles. Better results are obtained by relating $k$ to the strain energy in the body, as shown in $\S 4.3$, but a small improvement comes at the cost of considerable complexity.

Fitting $T[x, t]$ for all of the runs simultaneously with a single set of parameters resulted in much poorer fits than when fitting each run individually. This was ascribed to the fact that fast heating creates macroscopic thermal stress, because hotter regions are under compressive stress in the plane of the hot plate (owing to constraint by the cooler inner regions). Therefore, the fit was repeated by performing simultaneous fits to experiments of both slow and fast heating, allowing the thermal diffusivity to depend on strain energy density, $\Phi$, according to the equation:

$$
k=k_{1}+k_{2} \quad[\quad]
$$

where the function $\psi$ is shown in $\S 4.1$. Based on our experimental observation that $E_{d}$ and the thermal expansion coefficient, $\alpha$, of marble show the same temperature dependence, and lacking any theoretical justification for a different choice, we assume that the same function governs all three properties:

$$
[]=\frac{k[] k_{1}}{k_{2}}=\frac{E_{d}[]}{E_{0}}=\frac{1 \quad[]}{2}
$$

where the subscripted parameters are constants. 
This is the peer reviewed version of the following article: Sassoni E., Graziani G., Franzoni E., Scherer G.W., New method for controllable accelerated aging of marble: use for testing of consolidants, Journal of the American Ceramic Society, which has been published in final form at DOI: 10.1111/jace.15522. This article may be used for non-commercial purposes in accordance with Wiley Terms and Conditions for Use of Self-Archived Versions.

The procedure for finding $\psi[\Phi]$ is explained in detail in the Supplementary Material. Briefly, we begin by recognizing that each grain of calcite undergoes highly anisotropic dimensional change as the temperature rises or falls, but the grain is constrained within a polycrystalline matrix with a more or less isotropic expansion coefficient. (The linear thermal expansion coefficient of calcite, in units of $10^{-6} /{ }^{\circ} \mathrm{C}$, is about +25 along the c-axis and -5.6 normal to the c-axis, for a volumetric average of +4.6 , while the value for polycrystalline rocks is in the range of $8 \pm 4^{23}$.) Walsh has analyzed the effect of strain energy on expansion of marble, but his equations apply to small temperature intervals, where the opening of grain boundaries does not influence the thermal or elastic properties ${ }^{23}$. We regard the latter properties as highly important, so we employ a simplified geometric model to take them into account: we treat an individual grain of calcite as a sphere with a linear expansion of $4.6 \times 10^{-6} /{ }^{\circ} \mathrm{C}$ surrounded by an isotropic matrix whose properties vary with temperature; the latter are taken from our direct measurements on Carrara marble. If the sample is heated rapidly, there are additional stresses from the macroscopic temperature gradient that are easily calculated. Their effect can be included by imposing the hydrostatic component of those stresses on the outer surface of the composite sphere model, as explained in the Supplementary Material. Obviously, this is a highly approximate model, because the calcite grain is not a sphere, and it has highly anisotropic thermal and elastic properties, so that expansion results in local shear stresses that are neglected; moreover, the anisotropy of the polycrystalline matrix is ignored. Nevertheless, the fact that the model adequately reproduces the temperature distribution inside the sample, which depends on the evolving $k[x, t]$, indicates that the model roughly captures the influence of stress on heat transfer and consequent damage.

To relate the strain energy to the changes in physical properties, we make use of the theory of Budiansky and O'Connell ${ }^{24}$, which predicts the influence of cracks at grain boundaries on the 
This is the peer reviewed version of the following article: Sassoni E., Graziani G., Franzoni E., Scherer G.W., New method for controllable accelerated aging of marble: use for testing of consolidants, Journal of the American Ceramic Society, which has been published in final form at DOI: 10.1111/jace.15522. This article may be used for non-commercial purposes in accordance with Wiley Terms and Conditions for Use of Self-Archived Versions.

elastic properties of a body. The analysis proceeds as follows (the details are explained in the Supplementary Material):

(i) From the change in $E_{d}$ with temperature following isothermal treatments, we can use the theory ${ }^{24}$ to infer the crack density, $\rho[T]$.

(ii) The theory ${ }^{24}$ predicts the bulk and shear moduli and Poisson's ratio in the damaged material as functions of $\rho$.

(iii) Using those properties, together with the measured thermal expansion coefficient, in the composite sphere model, we find $\Phi$ as a function of $T$ (in the absence of a temperature gradient); then we can establish the functional dependence of $\rho$ on $\Phi$.

(iv) Given $E_{d}[T]$ from experiment, $\rho[T]$ from (i), and $\rho[\Phi]$ from (iii), we can find $\psi[\Phi]$ from Eq. (5)

Calculation of stresses created by rapid heating requires iteration, because the strain energy depends on the moduli, and the moduli depend on the strain energy. In the first iteration, we use Eqs. (2) and (3); subsequent iterations use properties from Eq. (5) with $\Phi$ from the preceding iteration. A satisfactory result for $\psi[\Phi]$ is obtained after 4 iterations. A joint fit to all of the data sets using Eq. (5) results in fits to the temperature that are similar to those obtained from individual fits to each set using Eq. (2). The results are summarized in $\S 4.3$.

The dynamic elastic modulus $E_{d}$ was adopted as a reliable parameter to describe the damage caused by heating, because in marbles $E_{d}$ has been demonstrated to be highly sensitive to formation of micro-cracks ${ }^{25,26}$ and quantitative correlations have been established between $E_{d}$ and strength (although the scatter is significant) ${ }^{27,28}$.

Once the temperature change with time and distance from the plate can be predicted from the model, and the decrease in $E_{d}$ can be related to that temperature change, it is possible to 
This is the peer reviewed version of the following article: Sassoni E., Graziani G., Franzoni E., Scherer G.W., New method for controllable accelerated aging of marble: use for testing of consolidants, Journal of the American Ceramic Society, which has been published in final form at DOI: 10.1111 /jace.15522. This article may be used for non-commercial purposes in accordance with Wiley Terms and Conditions for Use of Self-Archived Versions.

calculate what heating temperature and time will lead to a certain profile in $E_{d}$. An example of the model application is presented in $\S 4.3$.

\section{EXPERIMENTAL PROCEDURE}

\subsection{Marble}

Experimental tests were carried out on $5 \times 5 \times 1 \mathrm{~cm}^{3}$ prismatic samples of Carrara marble, sawn from a slab provided by BasketweaveMosaics.com (USA). This lithotype is a white variety of marble quarried in Carrara (Italy), which has been widely used in historic architecture and sculpture, so that it is likely the most widely studied type of marble in the literature ${ }^{1,5,7,8,14,19,20}$. It is composed of calcite grains, with only ppm impurities (mainly dolomite), and it has very low open porosity $(<0.2 \%)^{29}$. An SEM image illustrating marble microstructure and grain size (obtained by acid etching of a polished surface to expose the grain boundaries) is reported in Figure 1.

\subsection{Temperature dependence of the thermal diffusivity}

The thermal diffusivity was determined by putting marble samples onto a hotplate at a certain initial temperature and measuring the variation in temperature inside the sample as a function of time and distance from the plate. To measure the temperature inside the sample, grooves were cut in a $5 \times 5 \times 1 \mathrm{~cm}^{3}$ marble sample to allow the insertion of thermocouples to measure the marble temperature at increasing distance from the heating plate. First, the grooves $(1 \mathrm{~mm}$ thickness) were cut in 4 different samples (Figure 2a), then the samples with the grooves were coupled with 4 other samples without grooves, so as to obtain 4 "sandwich samples" (Figure $2 \mathrm{~b}$ ). The sandwiches were held together by a layer of insulating materials (described below) and an external band of tape. Finally, a thermocouple was inserted into each groove (so as to reach a 
This is the peer reviewed version of the following article: Sassoni E., Graziani G., Franzoni E., Scherer G.W., New method for controllable accelerated aging of marble: use for testing of consolidants, Journal of the American Ceramic Society, which has been published in final form at DOI: 10.1111/iace.15522. This article may be used for non-commercial purposes in accordance with Wiley Terms and Conditions for Use of Self-Archived Versions.

distance of 1,2, 3 and $4 \mathrm{~cm}$ from the hotplate), while 2 additional thermocouples were used to measure the temperature at the contact point of the sample with the hotplate $($ distance $=0 \mathrm{~cm})$ and on top of the sample (distance $=5 \mathrm{~cm}$ ), as illustrated in Figure 2c. The 6 thermocouples were then connected to an acquisition system (IOtech Personal Daq/56 and DASYLab V 7.00.05 software).

To prevent heat losses, the sides and the top of the "sandwich samples" were wrapped with a high-temperature-resistant insulator (Insulfrax S Blanket, kindly supplied by McNeil Inc.), not illustrated in Figure 2c for readability's sake. Four different experiments were run: three of "slow heating" from room temperature to $400{ }^{\circ} \mathrm{C}$ ( 2 samples) or $200{ }^{\circ} \mathrm{C}$ (1 sample) and one of "fast heating" from $200{ }^{\circ} \mathrm{C}$ to $400{ }^{\circ} \mathrm{C}\left(400{ }^{\circ} \mathrm{C}\right.$ being the maximum temperature that the thermocouples could read). In all experiments, the temperature increase as a function of time and distance from the plate was measured. Then, by solving Eq. (1) numerically and fitting to the experimental data, the parameters $k_{1}, k_{2}$ and $\lambda_{k}$ were obtained.

The analysis was performed by solving Eq. (1) with the NDSolve routine in Mathematica ${ }^{\circledR}$ (Mathematica v. 11.0, Wolfram Research, Inc., Champaign, Illinois, 2016) with properties given by Eq. (5). The parameters were adjusted using a simplex scheme ${ }^{30}$ to obtain the best fit to the measured temperature and time data.

\subsection{Temperature dependence of dynamic elastic modulus}

The correlation between $T$ and $E_{d}$ was determined by heating $5 \times 5 \times 1 \mathrm{~cm}^{3}$ marble samples at $100,200,300$ and $400{ }^{\circ} \mathrm{C}$ for 1 hour in an oven and then measuring the resulting decrease in ultrasonic pulse velocity, $v . E_{d}$ was calculated according to the formula $E_{d}=d v^{2}$, where $d$ is the density of the marble $\left(2670 \mathrm{~kg} / \mathrm{m}^{3}\right)$. The velocity was measured across the $5 \mathrm{~cm}$ sides of the samples using a PUNDIT instrument with $54 \mathrm{kHz}$ transducers and a rubber couplant between the sample and the transducers. 
This is the peer reviewed version of the following article: Sassoni E., Graziani G., Franzoni E., Scherer G.W., New method for controllable accelerated aging of marble: use for testing of consolidants, Journal of the American Ceramic Society, which has been published in final form at DOI: 10.1111/iace.15522. This article may be used for non-commercial purposes in accordance with Wiley Terms and Conditions for Use of Self-Archived Versions.

\subsection{Consolidation}

The suitability of the artificially weathered samples, obtained as described above, to test new consolidants for marble was evaluated as follows. Two samples heated at $200{ }^{\circ} \mathrm{C}$ for $20 \mathrm{sec}$ and two samples heated at $300{ }^{\circ} \mathrm{C}$ for $20 \mathrm{sec}$ were treated using a phosphate consolidant. This treatment is based on the idea of bonding the surfaces of cracks between calcite grains by forming hydroxyapatite (HAP, $\left.\mathrm{Ca}_{10}\left(\mathrm{PO}_{4}\right)_{6}(\mathrm{OH})_{2}\right)$ inside the cracks $^{13}$. HAP is formed by impregnating marble with an aqueous solution of diammonium hydrogen phosphate (DAP, $\left.\left(\mathrm{NH}_{4}\right)_{2} \mathrm{HPO}_{4}\right)^{13}$. Samples were treated with the most recent formulation of the HAP-treatment ${ }^{31}$, consisting in a 0.1 M DAP solution also containing $0.1 \mathrm{mM} \mathrm{CaCl}_{2}$ (added to increase marble coverage by $\mathrm{HAP}^{32,33}$ ) and $10 \mathrm{vol} \%$ ethanol (added to favor HAP formation even at low DAP concentrations ${ }^{34,35}$ ). Samples were treated by vacuum impregnation, to ensure penetration of the DAP solution into the microcracks. After immersion in the DAP solution for 24 hours, the samples were rinsed with deionized water to remove excess DAP and dried at room temperature. The consolidating action of the HAPtreatment was assessed by measuring the increase in $E_{d}$, which is often used to evaluate the ability of consolidants to re-establish the cohesion between grains ${ }^{13,36}$. It is true that an $E_{d}$ increase might be registered even when micro-cracks are filled with a compound that is not actually bonding the micro-crack surfaces (e.g., soluble salts ${ }^{37}$ ), so that no increase in mechanical strength is experienced; however, previous studies have demonstrated that $E_{d}$ increases owing to HAP formation inside the micro-cracks are linked to actual increases in tensile strength ${ }^{13}$ and resistance to abrasion ${ }^{20}$. The increase in $E_{d}$ after consolidation was assessed by repeating the $E_{d}$ measurements. One sample for each condition was also subjected to a second consolidation treatment in the same conditions as above, to check the benefit of double treatments. The consolidating action of the hydroxyapatite formed inside the micro-cracks was also qualitatively assessed by observing a fracture surface of a sample preliminarily damaged at $200{ }^{\circ} \mathrm{C}$ and then 
This is the peer reviewed version of the following article: Sassoni E., Graziani G., Franzoni E., Scherer G.W., New method for controllable accelerated aging of marble: use for testing of consolidants, Journal of the American Ceramic Society, which has been published in final form at DOI: 10.1111/jace.15522. This article may be used for non-commercial purposes in accordance with Wiley Terms and Conditions for Use of Self-Archived Versions.

treated once. A field emission gun environmental scanning electron microscope (FEG-ESEM, FEI Quanta 200) was used.

\section{RESULTS AND DISCUSSION}

\subsection{Temperature dependence of the thermal diffusivity}

The profiles of temperature increase registered by the 6 thermocouples during the heating experiments are reported in Figure 3, for a sample slowly heated to $400{ }^{\circ} \mathrm{C}$ by contact with a plate initially cold, and in Figure 4, for a sample rapidly heated to $400{ }^{\circ} \mathrm{C}$ by contact with a plate initially at $200{ }^{\circ} \mathrm{C}$. In both cases, as expected, the final maximum temperature is lower at increasing depth from the plate; however, when the lower surface reached $400{ }^{\circ} \mathrm{C}$, in the case of slow heating the sample top reached a temperature above $200^{\circ} \mathrm{C}$, whereas in the case of fast heating the sample top is well below $100^{\circ} \mathrm{C}$.

By solving Eq. (1) numerically, a rather good fit to the experimental data was obtained for both slow and fast heating (Figure 3 and Figure 4, where black curves indicate the experimental data and the red dotted curves indicate the fit). However, the $k_{1}, k_{2}$ and $\lambda_{\mathrm{k}}$ parameters necessary to describe the temperature-dependence of $k$ with Eq. (2) were significantly different for slow and fast heating rates. Specifically, fits to the three experiments with slow heating provided a substantially identical trend of $k$ versus temperature, but the experiments with fast heating provided a significantly different trend, as shown in Figure 5a.

When the joint fit is performed with properties described by Eq. (5), better results are achieved, as illustrated in Figure 6. Although improved compared to fits using Eq. (1) (reported in Figure 5b), the fit is imperfect, particularly at early times. This is unfortunate because, for the purpose of producing artificially aged samples with a gradient in properties, the contact time with 
This is the peer reviewed version of the following article: Sassoni E., Graziani G., Franzoni E., Scherer G.W., New method for controllable accelerated aging of marble: use for testing of consolidants, Journal of the American Ceramic Society, which has been published in final form at DOI: 10.1111 /jace.15522. This article may be used for non-commercial purposes in accordance with Wiley Terms and Conditions for Use of Self-Archived Versions.

the hot plate is expected to be quite short (otherwise heat and consequent damage will propagate all through the sample). Nevertheless, the accuracy of the prediction is sufficient for identifying the thermal treatment needed to achieve the desired level of damage, as demonstrated in $\S 4.3$.

\subsection{Temperature dependence of dynamic elastic modulus}

The decrease in $E_{d}$ with temperature is illustrated in Figure 7, where the dots are the experimental values and the curve is a fit to Eq. (3). The reduction in $E_{d}$ (from an initial value of $\left.E_{0} \approx 65 \mathrm{GPa}\right)$ as temperature increases is due to the formation of new micro-cracks that open at grain boundaries as a result of anisotropic thermal expansion of the calcite crystals, leading to a loss of cohesion between grains ${ }^{1}$. Notably, after heating to $200{ }^{\circ} \mathrm{C}$ the $E_{d}$ is already reduced to $30 \%$ of its initial value and heating to higher temperature causes a relatively small additional damage. This high sensitivity to temperature (much more pronounced than that measured in a previous study on limestone $\mathrm{i}^{13}$ ) is a consequence of the very tight packing of calcite grains in unweathered marble, so that no grain deformation upon heating can take place without causing stress ${ }^{19}$.

\subsection{Validation of the mathematical model}

The level of damage that we wanted to reproduce was based on the characterization of a naturally weathered marble sample analyzed in a previous study ${ }^{20}$. After exposure in the field for some 150 years, the $E_{d}$ of this marble sample had decreased by $\sim 40 \%$ in the first $1 \mathrm{~cm}$ from the surface, by $\sim 10 \%$ between 1 and $2 \mathrm{~cm}$ and was basically unchanged at greater depth ${ }^{20}$. Considering the intrinsic variability of damage from case to case, for simplicity’s sake a reduction in $E_{d}$ of $\sim 40 \%$ in the first $1 \mathrm{~cm}$, with no damage at greater depth, was chosen as the target in the present study. The mathematical model predicts that a sample put in contact with a hotplate at $200{ }^{\circ} \mathrm{C}$ for 20 seconds will experience a $70 \%$ decrease in $E_{d}$ at the surface and no decrease at a depth of $1 \mathrm{~cm}$, 
This is the peer reviewed version of the following article: Sassoni E., Graziani G., Franzoni E., Scherer G.W., New method for controllable accelerated aging of marble: use for testing of consolidants, Journal of the American Ceramic Society, which has been published in final form at DOI: 10.1111/iace.15522. This article may be used for non-commercial purposes in accordance with Wiley Terms and Conditions for Use of Self-Archived Versions.

corresponding to an average $35 \%$ decrease in the first $1 \mathrm{~cm}$. To verify the model predictions, 3 samples $\left(5 \times 5 \times 1 \mathrm{~cm}^{3}\right)$ were damaged by contact with a hotplate at $200{ }^{\circ} \mathrm{C}$ for 20 seconds and the consequent $E_{d}$ decrease was determined. The $E_{d}$ measurement was performed in the first $1 \mathrm{~cm}$ from the $5 \times 1 \mathrm{~cm}^{2}$ surface in contact with the hot plate and at a distance of 4 to $5 \mathrm{~cm}$ from the heated surface, to verify that this part was not damaged, as foreseen by the model. More refined profiling of $E_{d}$ (at distances between 1 and $4 \mathrm{~cm}$ from the heated surface) was not possible because of the size of the available transducers $(5 \mathrm{~cm})$. By putting only the most external $1 \mathrm{~cm}$ part of the samples between the transducers, it was possible to reliably measure $E_{d}$ in these external parts, but no information could be obtained between 1 and $4 \mathrm{~cm}$ from the heated surface. To verify the versatility of the model, 3 other samples were damaged in more severe conditions $\left(300{ }^{\circ} \mathrm{C}\right.$ for 20 seconds) and then again the $E_{d}$ decrease predicted by the model was verified experimentally.

The comparison between the $E_{d}$ decrease predicted by the model and measured experimentally is illustrated in Figure 8 . On the surface, $E_{d}$ is predicted to be reduced to $30 \%$ and $15 \%$ of its initial value after heating at $200{ }^{\circ} \mathrm{C}$ and $300{ }^{\circ} \mathrm{C}$, respectively, in accordance with the $E_{d}[T]$ relationship reported in Figure 7. For both heating temperatures, the damage is predicted to be mostly limited to the first $1 \mathrm{~cm}$ from the plate, whereas the remaining part of the sample should remain unaltered (Figure 8a). According to the model, in the first $1 \mathrm{~cm}$ the average value of $E_{d}$ is expected to be reduced to $65 \%$ of its initial value (35\% $E_{d}$ reduction) after heating at $200{ }^{\circ} \mathrm{C}$, and to $58 \%$ (42\% $E_{d}$ reduction) after heating at $300{ }^{\circ} \mathrm{C}$ (Figure $8 \mathrm{~b}$ ). When the same conditions of heating temperature and time were adopted experimentally to produce aged samples, the values of $E_{d}$ decrease reported in Figure $8 \mathrm{~b}$ were obtained. In both conditions, the experimental results exhibited very good agreement with what was predicted by the model.

Additional macroscopic evaluation of the depth of damage induced by heating at 200 and $300{ }^{\circ} \mathrm{C}$ for 20 seconds was obtained by placing a drop of methylene blue solution $(10 \mathrm{~g} / \mathrm{L})$ onto 
This is the peer reviewed version of the following article: Sassoni E., Graziani G., Franzoni E., Scherer G.W., New method for controllable accelerated aging of marble: use for testing of consolidants, Journal of the American Ceramic Society, which has been published in final form at DOI: 10.1111/iace.15522. This article may be used for non-commercial purposes in accordance with Wiley Terms and Conditions for Use of Self-Archived Versions.

the sample face that had been put in contact with the hotplate. After drying, the depth of penetration of the methylene blue solution into the micro-cracks developed after artificial weathering was evaluated. Cross sections of the stained samples were obtained by dry sawing (to avoid solubilizing the methylene blue stain) and by fracturing with a chisel.

The cross sections of unweathered and weathered samples are illustrated in Figure 9a. Because holes with $3 \mathrm{~mm}$ diameter had been drilled starting from the heated surface toward the interior, the depth of the methylene blue stain can be observed in the internal surface of these holes. (The holes had been drilled in hopes of assessing the variation in micro-drilling resistance with depth. However, for the given specimen size and marble grain size, the results obtained with the available instrument exhibited very high scatter, even in the unweathered specimens. This made it impossible to reliably assess any variation of the micro-drilling resistance with depth in the weathered samples.) As a consequence of the micro-cracks opened after the accelerated ageing procedures, the depth of penetration of the methylene blue solution into the thermally aged samples was markedly higher than in the fresh sample. In the aged samples, the staining gradually decreased from the heated surface towards the interior, a slight color difference being still visible at $1 \mathrm{~cm}$ depth, as expected. On the contrary, in the fresh sample the staining was barely visible. In terms of penetration depth, the two samples heated at different temperatures do not exhibit a dramatic difference, which is consistent with the prediction by the model. At the same time, the sample heated at $300{ }^{\circ} \mathrm{C}$ exhibits more intense staining near the surface, which is consistent with the higher near-surface damage expected in this sample. The difference in the stain color between the two heated samples is due to the different time elapsed between the staining and the observation (a few days in the case of the sample heated at $200{ }^{\circ} \mathrm{C}$, a few hours in the case of the sample heated at 300 ${ }^{\circ} \mathrm{C}$ ). A fracture cross-section of the sample heated at $300{ }^{\circ} \mathrm{C}$ was also observed against the light: as 
This is the peer reviewed version of the following article: Sassoni E., Graziani G., Franzoni E., Scherer G.W., New method for controllable accelerated aging of marble: use for testing of consolidants, Journal of the American Ceramic Society, which has been published in final form at DOI: 10.1111/iace.15522. This article may be used for non-commercial purposes in accordance with Wiley Terms and Conditions for Use of Self-Archived Versions.

illustrated in Figure 9b, a progressive fading of the blue stain was assessed, down to a depth of about $1 \mathrm{~cm}$.

Marble samples artificially damaged by contact with the hotplate exhibit features quite close to those of naturally weathered marble (namely a decrease in $E_{d}$ of $\sim 40 \%$ in the first $1 \mathrm{~cm}$ from the surface, while the underlying substrate is still sound $\left.{ }^{20}\right)$. These samples can therefore be regarded as suitable to investigate the performance of stone consolidants, whose main objective is to re-establish cohesion between grains in the weathered part, without causing over-consolidation (i.e. excessive stiffening) of the sound part ${ }^{10,38,39}$.

\subsection{Consolidation}

When samples artificially aged by brief contact with the hotplate at $200^{\circ} \mathrm{C}$ and $300^{\circ} \mathrm{C}$ were treated by the hydroxyapatite treatment, a substantial increase in $E_{d}$ was achieved in both cases (Figure 10). As expected, the ability to restore the initial $E_{d}$ was more pronounced in the sample with the least damage (hotplate at $200{ }^{\circ} \mathrm{C}$ instead of $300{ }^{\circ} \mathrm{C}$ ). This increase in $E_{d}$ (which can be taken as representative of an increase in strength, as discussed in § 3.4 ) was made possible by formation of hydroxyapatite inside the micro-cracks, as revealed by SEM observation (Figure 11). However, in neither case was the original $E_{d}$ fully restored in the lower $1 \mathrm{~cm}$. A second consolidation treatment, identical to the first one, was then applied. In the case of the sample decayed at $200{ }^{\circ} \mathrm{C}$ (Figure 9,a), $E_{d}$ was completely restored after the second treatment, with no excessive over-consolidation of the upper sound part (increases in bending strength, compressive strength and modulus of elasticity up to $+125 \%$ of the undamaged value ${ }^{40}$ and increases in tensile strength up to $+150 \%{ }^{41}$ of the undamaged value have been identified in the literature as thresholds beyond which consolidation is excessive - the same percentage increases were assumed here as references to evaluate the $E_{d}$ increases, which resulted always lower than any of these thresholds). 
This is the peer reviewed version of the following article: Sassoni E., Graziani G., Franzoni E., Scherer G.W., New method for controllable accelerated aging of marble: use for testing of consolidants, Journal of the American Ceramic Society, which has been published in final form at DOI: 10.1111/iace.15522. This article may be used for non-commercial purposes in accordance with Wiley Terms and Conditions for Use of Self-Archived Versions.

The results achieved on this sample, initially exhibiting a damage condition very close to that of naturally weathered marble, indicate that the treatment with hydroxyapatite consolidant is suitable, being both effective in enhancing mechanical properties and compatible from a mechanical point of view, as it does not cause over-consolidation. In the case of the sample decayed at $300{ }^{\circ} \mathrm{C}$, the second treatment raised $E_{d}$ up to $93 \%$ of its initial level. Although not complete, this increase in mechanical properties can be considered satisfactory as well, considering that this sample had been weathered to a higher (but still realistic) extent compared to the sample coming from the field.

\section{CONCLUSIONS}

In this paper, a novel method for accelerated aging of marble was proposed, to produce samples with a gradient in properties resembling the condition of marble elements exposed outdoors (characterized by more diffused micro-cracking near the surface). Based on the results of the study, the following conclusions can be derived:

1) The mathematical model, which takes into account the dependence of the thermal diffusivity, thermal expansion coefficient, and dynamic elastic modulus upon temperature, allows prediction of the mechanical damage occurring in marble samples put in contact with a hot plate at a certain temperature for a certain time. Results obtained experimentally provided good confirmation of the model predictions. However, because of the limitation coming from the size of the available transducers (which do not provide sufficient spatial resolution), more detailed validation of the model seem opportune. In a future study, it would be ideal to obtain a profile of the damage to the stone (e.g., by using microidentation test).

2) To produce damage similar to that encountered in the field (e.g. a decrease in dynamic elastic modulus $E_{d}$ of $\sim 40 \%$ in the first $1 \mathrm{~cm}$ from the surface and no damage in the underlying 
This is the peer reviewed version of the following article: Sassoni E., Graziani G., Franzoni E., Scherer G.W., New method for controllable accelerated aging of marble: use for testing of consolidants, Journal of the American Ceramic Society, which has been published in final form at DOI: 10.1111/iace.15522. This article may be used for non-commercial purposes in accordance with Wiley Terms and Conditions for Use of Self-Archived Versions.

marble), the model prescribes that Carrara marble samples be put in contact with a hotplate at $200{ }^{\circ} \mathrm{C}$ for $20 \mathrm{sec}$. When these conditions were adopted experimentally, a very good agreement was found between the $E_{d}$ decrease predicted by the model in the first $1 \mathrm{~cm}$ of the sample ($35 \%)$ and that measured experimentally (-38\%). Similarly, when a more severe weathering condition (heating at $300{ }^{\circ} \mathrm{C}$ for $20 \mathrm{sec}$ ) was used to check the model versatility, very good agreement was again found between the calculated (-42\%) and the measured $(\sim 44 \%)$ values of $E_{d}$ decrease. This confirms the suitability of the mathematical model for preparing samples with a desired gradient in mechanical properties. The depth of damage was verified by penetration of dye, which indicated a gradient in damage extending to a depth of about $1 \mathrm{~cm}$.

3) The hydroxyapatite-based treatment, used to demonstrate the suitability of thermally aged samples for testing of consolidants, proved to be effective in improving the dynamic elastic modulus (completely restored after a double application) and compatible from a mechanical point of view (as it did not cause any excessive over-consolidation of the sound part of the sample).

In the case of other varieties of marble (including dolomitic marble), the properties of the specific lithotype would be needed to suitably adjust the mathematical model and obtain accurate predictions of the heating temperature and time. However, in case detailed property data are not available, the results of the present paper can be taken as a starting point and the appropriate time of contact for a different lithotype can be found by simple empirical tests.

The mathematical model developed in this paper can be applied to other polycrystalline materials, including ceramics, as well as natural stone, that develop internal stresses owing to anisotropic thermal and elastic properties. To obtain an analytical solution for such a complex problem requires severe assumptions (treating each grain as a sphere surrounded by an isotropic polycrystalline shell, and accounting for macroscopic thermal stresses by imposing the hydrostatic 
This is the peer reviewed version of the following article: Sassoni E., Graziani G., Franzoni E., Scherer G.W., New method for controllable accelerated aging of marble: use for testing of consolidants, Journal of the American Ceramic Society, which has been published in final form at DOI: 10.1111/jace.15522. This article may be used for non-commercial purposes in accordance with Wiley

Terms and Conditions for Use of Self-Archived Versions.

component on the composite sphere), so the results are highly approximate. The virtue of the method is that attributing the change in thermal properties to the magnitude of the strain energy explains why cooling is as damaging as heating. Moreover, the accuracy is sufficient to allow adequate prediction, using a single set of parameters, of the temperature distribution in marble samples heated slowly or rapidly.

\section{ACKNOWLEDGMENTS}

This project has received funding from the European Union's Horizon 2020 research and innovation program under the Marie Skłodowska-Curie grant agreement N. 655239 (HAP4MARBLE project, "Multi-functionalization of hydroxyapatite for restoration and preventive conservation of marble artworks").

\section{REFERENCES}

1. Siegesmund S, Ullemeyer K, Weiss T, Tschegg EK. Physical weathering of marbles caused by anisotropic thermal expansion. Int. J. Earth Sci. 2000;89:170-182.

2. ICOMOS (International Scientific Committee for Stone). Illustrated glossary on stone deterioration patterns. Champigny/Marne, France: Ateliers 30 Impression, 2008; p. 20-21.

3. Charola AE, Centeno SA, Normandin K. The New York Public Library: protective treatment for sugaring marble. J. Archit. Conserv. 2010;16:29-44.

4. Sàez-Pèrez MP, Rodrìguez-Gordillo $\mathrm{J}$. The influence of solar radiation on the deterioration of the marble columns in the Courtyard of the Lions In The Alhambra, Stud. Conserv. 2008;53:145-157. 
This is the peer reviewed version of the following article: Sassoni E., Graziani G., Franzoni E., Scherer G.W., New method for controllable accelerated aging of marble: use for testing of consolidants, Journal of the American Ceramic Society, which has been published in final form at DOI: 10.1111/iace.15522. This article may be used for non-commercial purposes in accordance with Wiley Terms and Conditions for Use of Self-Archived Versions.

5. Sassoni E, Franzoni E. Sugaring marble in the Monumental Cemetery in Bologna (Italy): characterization of naturally and artificially weathered samples and first results of consolidation by hydroxyapatite, Appl. Phys. A-Mater. 2014;117:1893-1906.

6. Lord Rayleigh. The Bending of Marble. Proceedings of the Royal Society of London. Series A, Containing Papers of a Mathematical and Physical Character 1934;144:266-279. http://www.jstor.org/stable/2935557

7. Royer-Carfagni G. Some considerations on the warping of marble façades: the example of Alvar Aalto's Finland Hall in Helsinki," Const. Build. Mater. 1999;13:449-457.

8. Siegesmund S, Ruedrich J, Koch A. Marble bowing: comparative studies of three different public building facades. Environ. Geol. 2008;56:473-494.

9. Marini P, Bellopede R. Bowing of marble slabs: evolution and correlation with mechanical decay. Constr. Build. Mater. 2009;23:2599-2605.

10. Amoroso GG, Fassina V. Stone decay and conservation. New York, USA: Elsevier; 1983.

11. Hansen E, Dohene E, Fidler J, Larson J, Martin B, Matteini M, et al. A review of selected inorganic consolidants and protective treatments for porous calcareous materials. Reviews in conservation. 2003;4:13-25.

12. Wheeler GS. Alkoxysilanes and the consolidation of stone. Los Angeles, USA: The Getty Conservation Institute; 2005.

13. Sassoni E, Naidu S, Scherer GW. The use of hydroxyapatite as a new inorganic consolidant for damaged carbonate stones. J. Cult. Herit. 2011;12:346-355.

14. Wheeler GS, Fleming SA, Ebersole S. Evaluation of some current treatments for marble. In: La conservation des monuments dans le bassin mediterraneen: Actes du $2^{\circ}$ symposium international [The conservation of momuments in the Mediterrenean Basin: Proceedings fo the $2^{\text {nd }}$ International Symposium]; 19-21/11/1991; Geneve, Switzerland; 1992:p. 439-443. 
This is the peer reviewed version of the following article: Sassoni E., Graziani G., Franzoni E., Scherer G.W., New method for controllable accelerated aging of marble: use for testing of consolidants, Journal of the American Ceramic Society, which has been published in final form at DOI: 10.1111/iace.15522. This article may be used for non-commercial purposes in accordance with Wiley Terms and Conditions for Use of Self-Archived Versions.

15. Franzoni E, Sassoni E, Scherer GW, Naidu S. Artificial weathering of stone by heating. J. Cult. Herit. 2013;14S:e85-e93.

16. Lubelli B, van Hees RPJ, Nijland TG, Bolhuis J. A new method for making artificially weathered stone specimens for testing of conservation treatments. J. Cult. Herit. 2015;16:698704.

17. Sena da Fonseca B, Ferreira Pinto AP, Piçarra S, Montemor MF. Artificial aging route for assessing the potential efficacy of consolidation treatments applied to porous carbonate stones. Mater. Design 2017;120:10-21.

18. Franzoni E, Sassoni E. Comparison between different methodologies for artificial deterioration of stone aimed at consolidants testing. In: Proceedings of the $12^{\text {th }}$ International Congress on Deterioration and Conservation of Stone. New York City, USA; 2012. http://iscs.icomos.org/pdf-files/NewYorkConf/fransass.pdf

19. Sassoni E, Franzoni E. Influence of porosity on artificial deterioration of marble and limestone by heating. Appl. Phys. A-Mater. 2014;115:809-816.

20. Sassoni E, Graziani G, Franzoni E. Repair of sugaring marble by ammonium phosphate: comparison with ethyl silicate and ammonium oxalate and pilot application to historic artifact. Mater. Design 2015;88:1145-1157.

21. Hanley EJ, Dewitt DP, Roy RF. The thermal diffusivity of eight well-characterized rocks for the temperature range 300-1000 k. Eng. Geol. 1978;12:31-47.

22. Shushakova V, Fuller Jr ER, Siegesmund S. Microcracking in calcite and dolomite marble: microstructural influences and effects on properties. Environ. Earth Sci. 2013;69:1263-1279.

23. Walsh JB. Theoretical bounds for thermal expansion, specific heat, and strain energy due to internal stress. J. Geophys. Res. 1973;87:7637-7646. 
This is the peer reviewed version of the following article: Sassoni E., Graziani G., Franzoni E., Scherer G.W., New method for controllable accelerated aging of marble: use for testing of consolidants, Journal of the American Ceramic Society, which has been published in final form at DOI: 10.1111/iace.15522. This article may be used for non-commercial purposes in accordance with Wiley Terms and Conditions for Use of Self-Archived Versions.

24. Budiansky B., O'Connell RJ. Elastic moduli of a cracked solid. Int. J. Solids Structures 1976;12:81-97.

25. Weiss T, Rasolofosaon PNJ, Siegesmund S. Ultrasonic wave velocities as a diagnostic tool for the quality assessment of marble. In: Siegesmund S, Weiss T, Vollbrecht A, eds. Natural stone, weathering phenomena, conservation strategies and case studies. Geological Society, London, Special Publications 2002;205:149-164.

26. Luque A, Ruiz-Agudo E, Cultrone G, Sebastiàn E, Siegesmund S. Direct observation of microcrack development in marble caused by thermal weathering. Environ. Earth Sci. 2011;62:1375-1386.

27. Ruedrich J, Knell C, Enseleit J, Rieffel Y, Siegesmund S. Stability assessment of marble statuaries of the Schlossbrücke (Berlin, Germany) based on rock strength measurement and ultrasonic wave velocities. Environ. Earth Sci. 2013;69:1451-1469.

28. Mahmutoğlu Y. Prediction of weathering by thermal degradation of a coarse-grained marble using ultrasonic pulse velocity. Environ. Earth Sci. 2017;76:435.

29. Naidu S, Blair J, Scherer GW. Acid-resistant coatings on marble. J. Am. Ceram. Soc. 2016;99:3421-3428.

30. Olsson DM. A sequential simplex program for solving minimization problems. J. Qual. Technol. 1974;6:53-57.

31. Sassoni E, Graziani G, Franzoni E, Scherer GW. Some recent findings on marble conservation by aqueous solutions of diammonium hydrogen phosphate. MRS Advances 2017;2:2021-2026.

32. Naidu S, Sassoni E, Scherer GW. New treatment for corrosion-resistant coatings for marble and consolidation of limestone. In: Jardins de Pierres - Conservation of stone in Parks, Gardens and Cemeteries. Paris, France; 2011:p. 289-294. 
This is the peer reviewed version of the following article: Sassoni E., Graziani G., Franzoni E., Scherer G.W., New method for controllable accelerated aging of marble: use for testing of consolidants, Journal of the American Ceramic Society, which has been published in final form at DOI: 10.1111/iace.15522. This article may be used for non-commercial purposes in accordance with Wiley Terms and Conditions for Use of Self-Archived Versions.

33. Naidu S, Scherer GW. Nucleation, growth and evolution of calcium phosphate films on calcite. J. Colloid. Interf. Sci. 2014;435:128-137.

34. Graziani G, Sassoni E, Franzoni E, Scherer GW. Hydroxyapatite Coatings For Marble Protection: Optimization Of Calcite Covering And Acid Resistance. Appl. Surf. Sci. 2016;368:241-257.

35. Ji X, Su P, Liu C, Li J, Tan H, Wu F, et al. A novel ethanol induced and stabilized nanorods: hydroxyapatite nanopeanut. J. Am. Ceram. Soc. 2015;98:1702-1705.

36. Ruedrich J, Weiss T, Siegesmund S. Thermal behavior of weathered and consolidated marbles. In: Siegesmund S, Weiss T, Vollbrecht A, eds. Natural stone, weathering phenomena, conservation strategies and case studies. Geological Society, London, Special Publications 2002;205:255-271.

37. Sassoni E, Graziani G, Franzoni E. An innovative phosphate-based consolidant for limestone. Part 2: Durability in comparison with ethyl silicate. Const. Build. Mater. 2016;102:931-942.

38. Italian Recommendation NORMAL 20/85. Conservazione dei materiali lapidei: Manutenzione ordinaria e straordinaria [Conservation of stone materials: ordinary and extraordinary maintenance]. Rome, Italy: Istituto Centrale per il Restauro (ICR), 1985.

39. Sassoni E, Graziani G, Franzoni E. An innovative phosphate-based consolidant for limestone. Part 1: effectiveness and compatibility in comparison with ethyl silicate. Constr. Build. Mater. 2016;102:918-930.

40. Delgado Rodrigues J, Grossi A. Indicators and ratings for the compatibility assessment of conservation actions. J Cult Herit 2007;8:32-43.

41. Maravelaki-Kalaitzaki P, Kallithrakas-Kontos N, Korakaki D, Agioutantis Z, Maurigiannakis S. Evaluation of silicon-based strengthening agents on porous limestones. Prog. Org. Coat. 2006;57:140-148. 


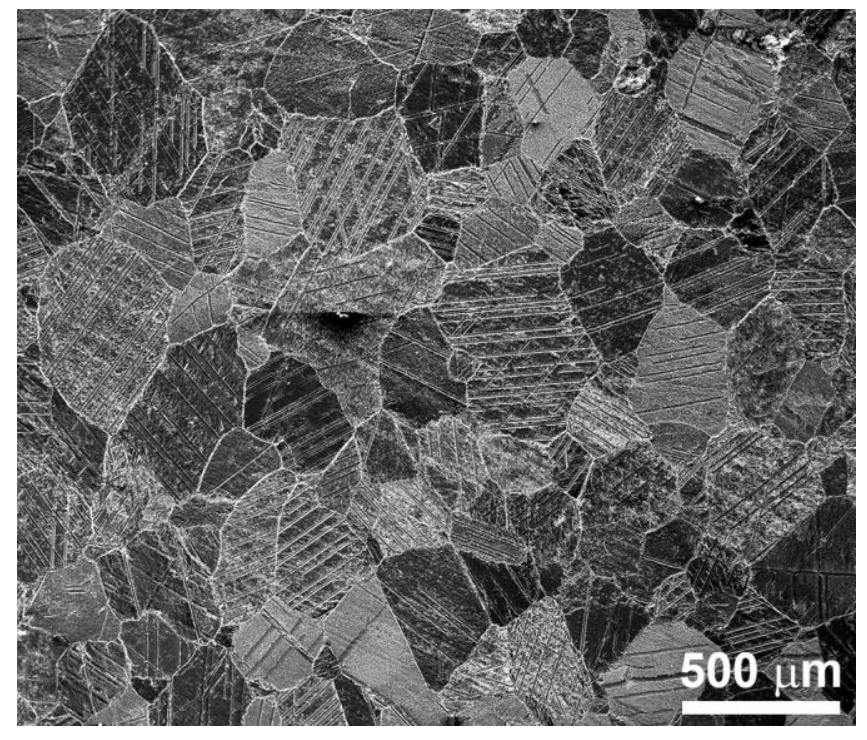

Figure 1. SEM image illustrating marble microstructure and grain size.
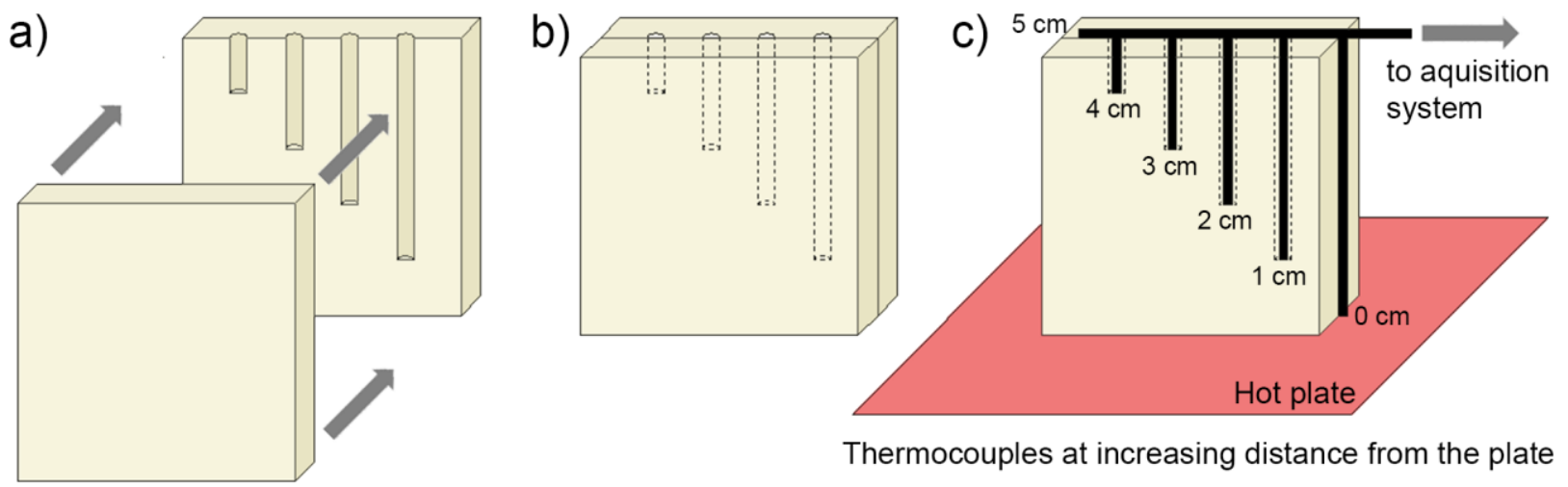

Thermocouples at increasing distance from the plate

Figure 2. Cartoon illustrating the experimental set up used to determine the thermal diffusivity $k$. a) Grooves were cut in marble samples to allow insertion of thermocouples at increasing distance from the plate; b) the samples with the grooves were coupled with others without grooves to form "sandwich samples"; c) the "sandwich samples" were instrumented with 6 thermocouples and insulated with a high temperature-resistant insulator (not illustrated in the picture). In this way, the temperature increase as a function of time and distance from the plate was measured. 
This is the peer reviewed version of the following article: Sassoni E., Graziani G., Franzoni E., Scherer G.W., New method for controllable accelerated aging of marble: use for testing of consolidants, Journal of the American Ceramic Society, which has been published in final form at DOI: 10.1111/jace.15522. This article may be used for non-commercial purposes in accordance with Wiley Terms and Conditions for Use of Self-Archived Versions.
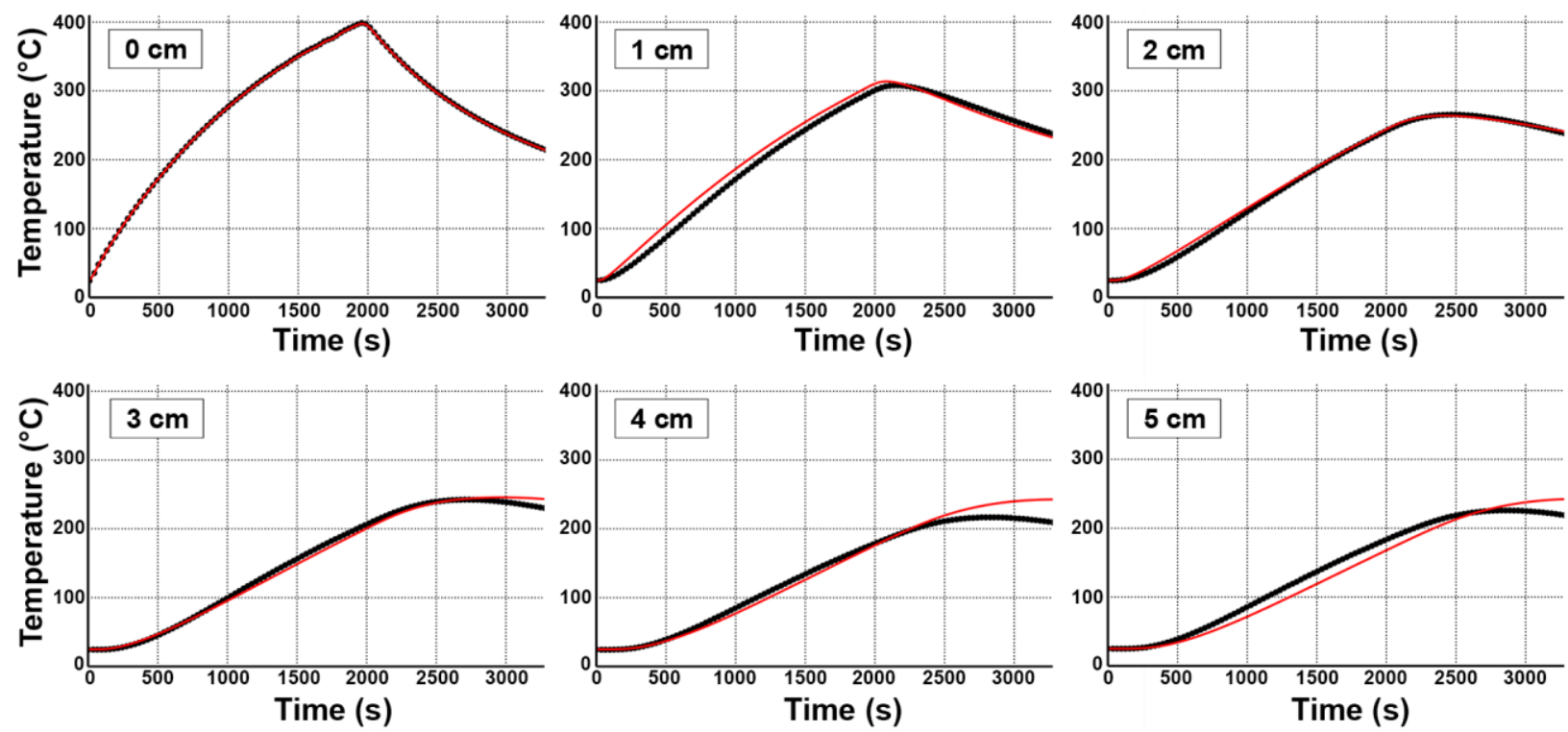

Figure 3. Temperature increase as a function of time and distance from the heating plate, for a sample slowly heated to $400{ }^{\circ} \mathrm{C}$ by contact with a plate initially at room temperature (black curve $=$ experimental data; red dotted curve $=$ fit $)$.
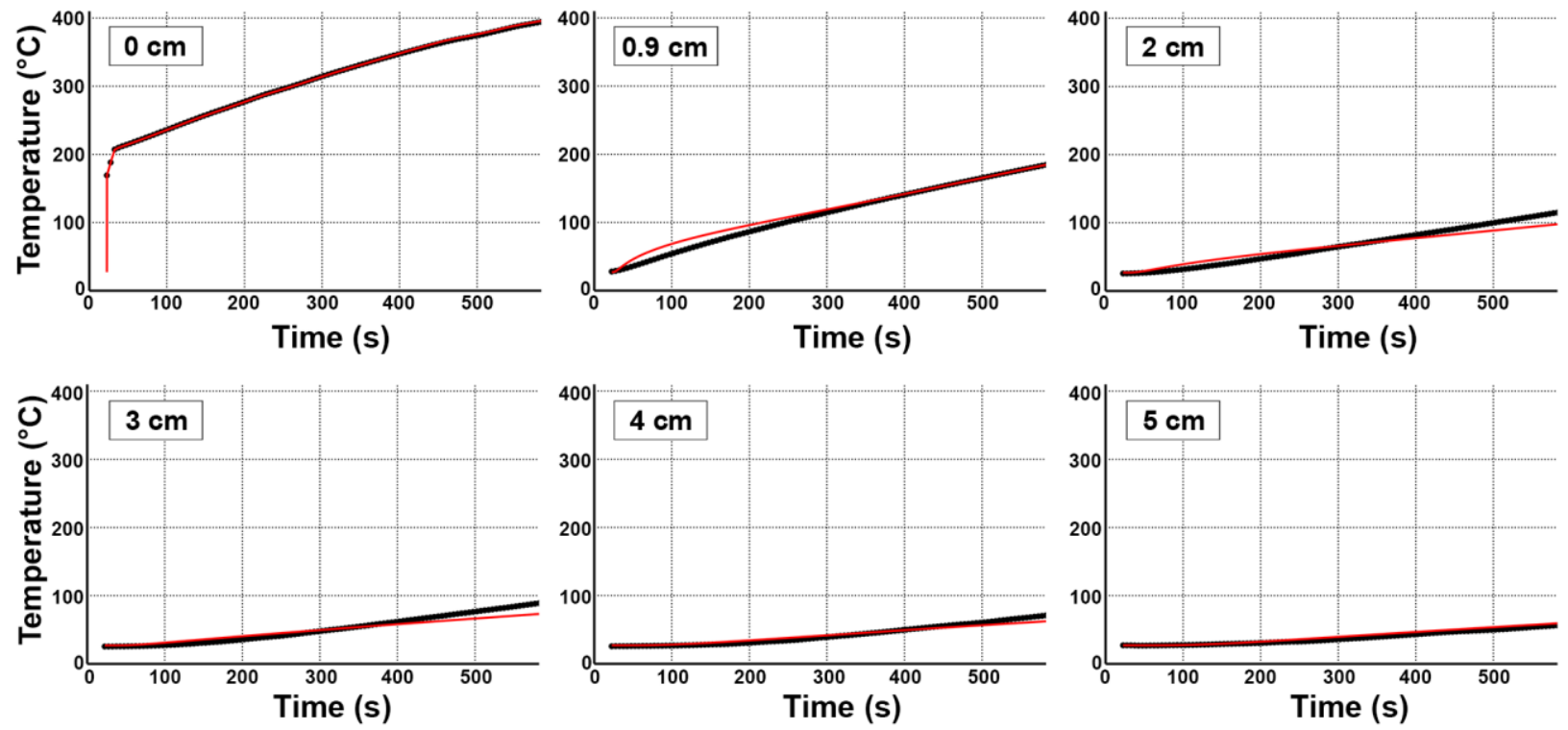

Figure 4. Temperature increase as a function of time and distance from the heating plate, for a sample rapidly heated to $400{ }^{\circ} \mathrm{C}$ by contact with a plate initially at $200{ }^{\circ} \mathrm{C}$ (black curve $=$ experimental data; red dotted curve $=$ fit $)$. 
a)

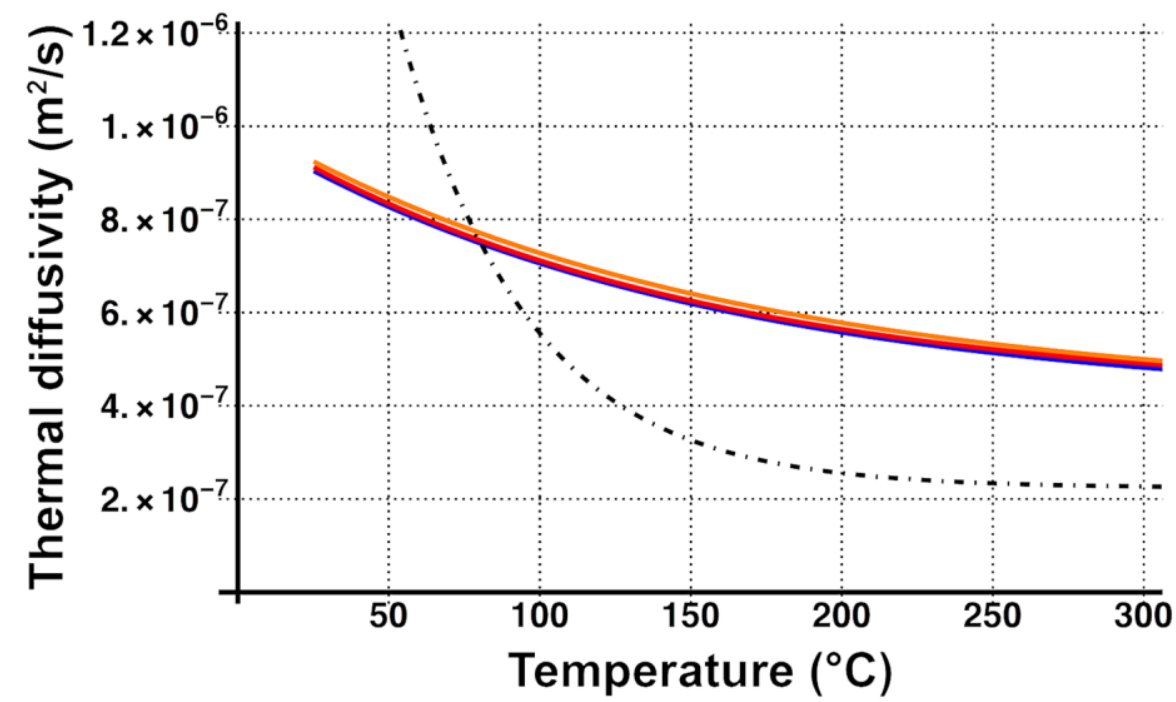

b)

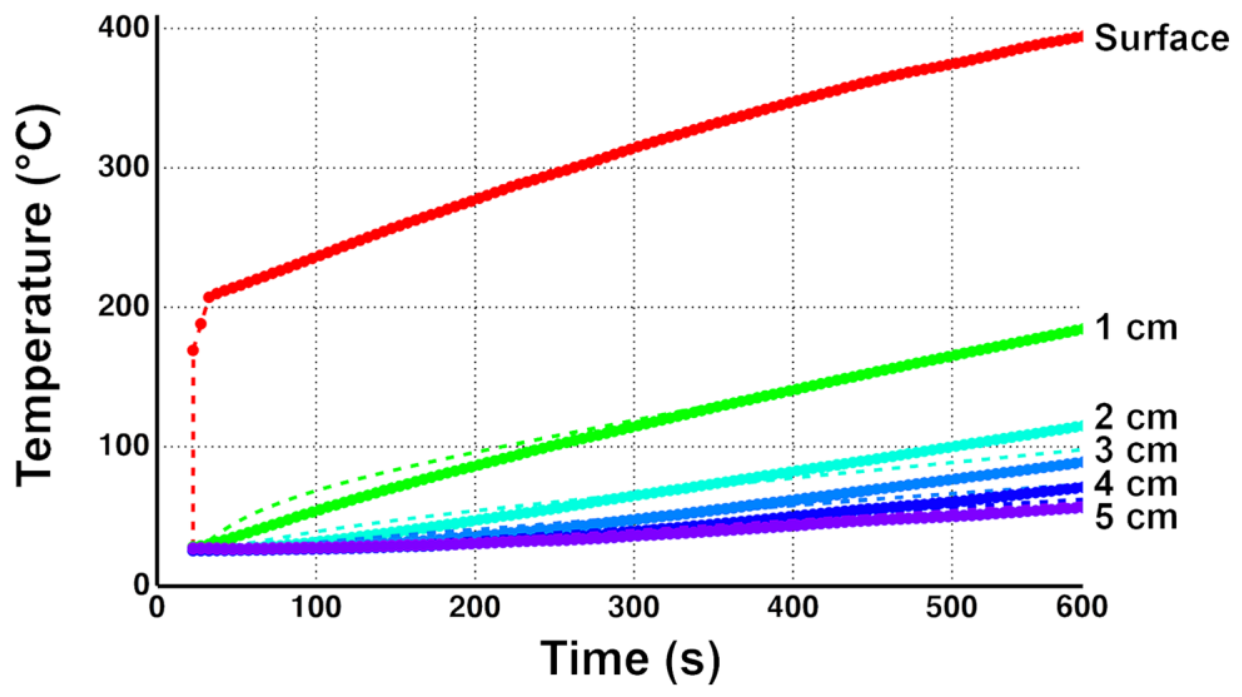

Figure 5. Results of the separate fit: (a) trend of $k$ variation with temperature, as calculated by fitting separately using Eq. (1) (the solid curves are best fits for samples heated slowly, while the dashed curve is for the sample heated quickly on a hotplate preheated to $200^{\circ} \mathrm{C}$ ); (b) temperature increase as a function of time and distance from the heating plate, for a sample rapidly heated to $400{ }^{\circ} \mathrm{C}$ by contact with a plate initially at $200{ }^{\circ} \mathrm{C}$, as determined experimentally (bold dots) and calculated (dashed curves) by using the $k$ function obtained from the separate fit. 
a)

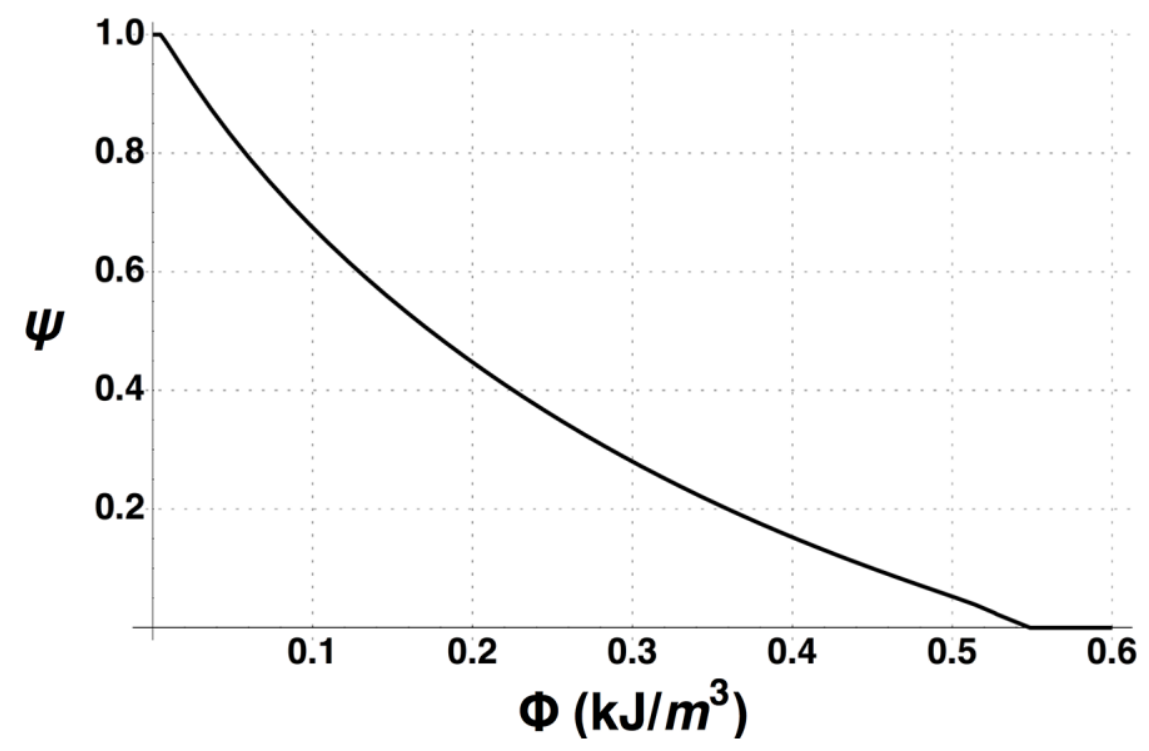

b)

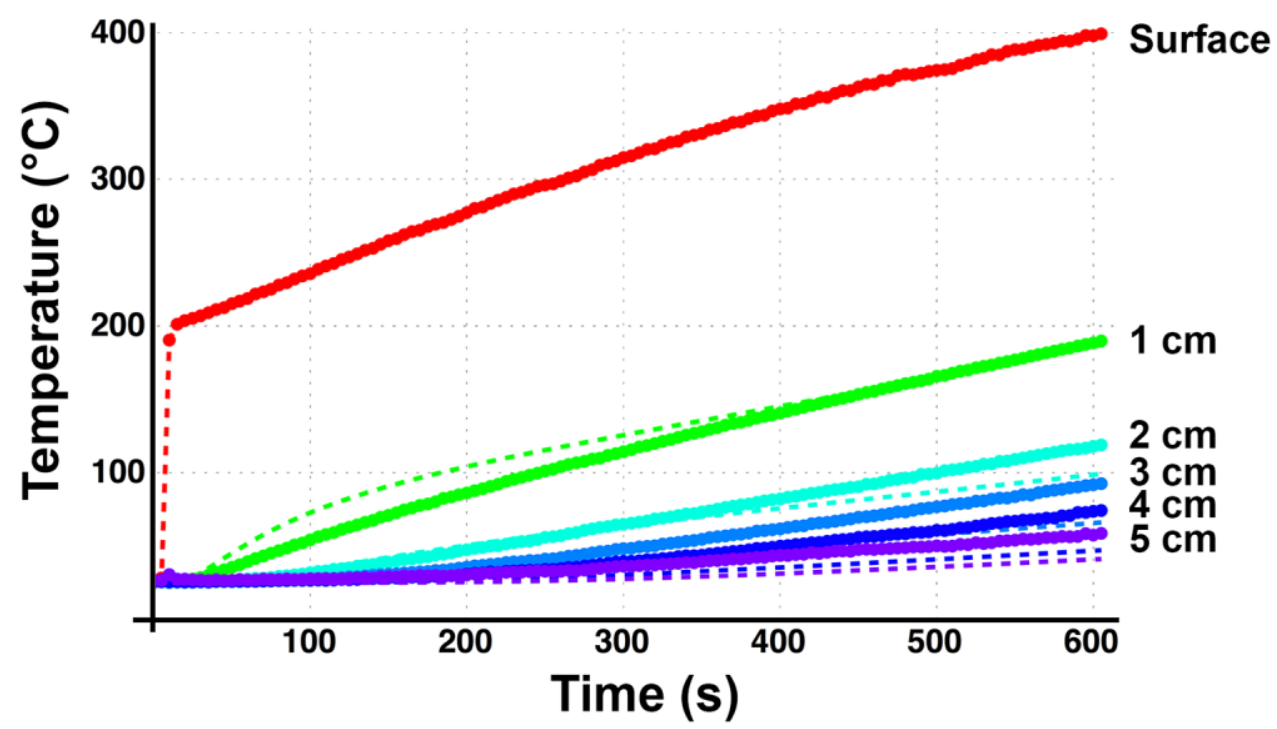

Figure 6. Results of the joint fit: (a) the function $\psi$, which governs the behavior of the thermal diffusivity of the marble matrix; (b) temperature increase as a function of time and distance from the heating plate, for a sample rapidly heated to $400{ }^{\circ} \mathrm{C}$ by contact with a plate initially at $200{ }^{\circ} \mathrm{C}$, as determined experimentally (bold dots) and calculated (dashed curves) by using the function $\psi$ in a joint fit of all the tests. 


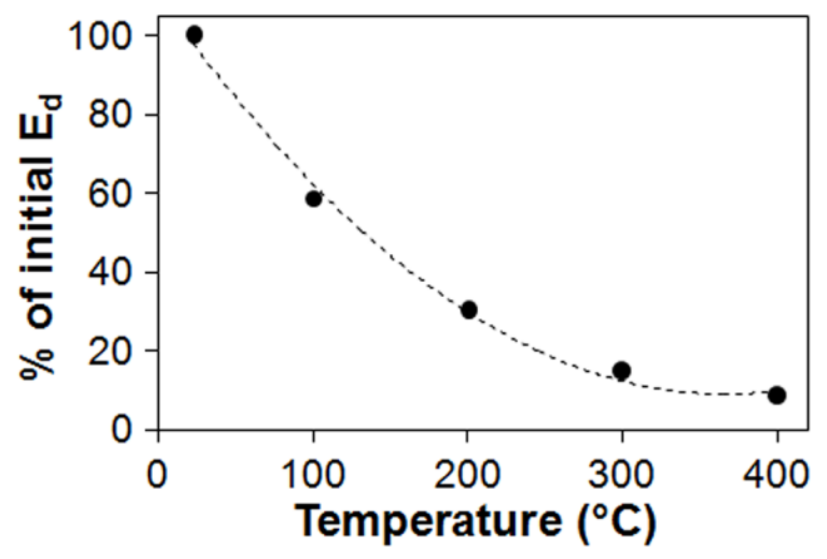

Figure 7. Reduction in dynamic elastic modulus $E_{d}$ as a function of heating temperature.
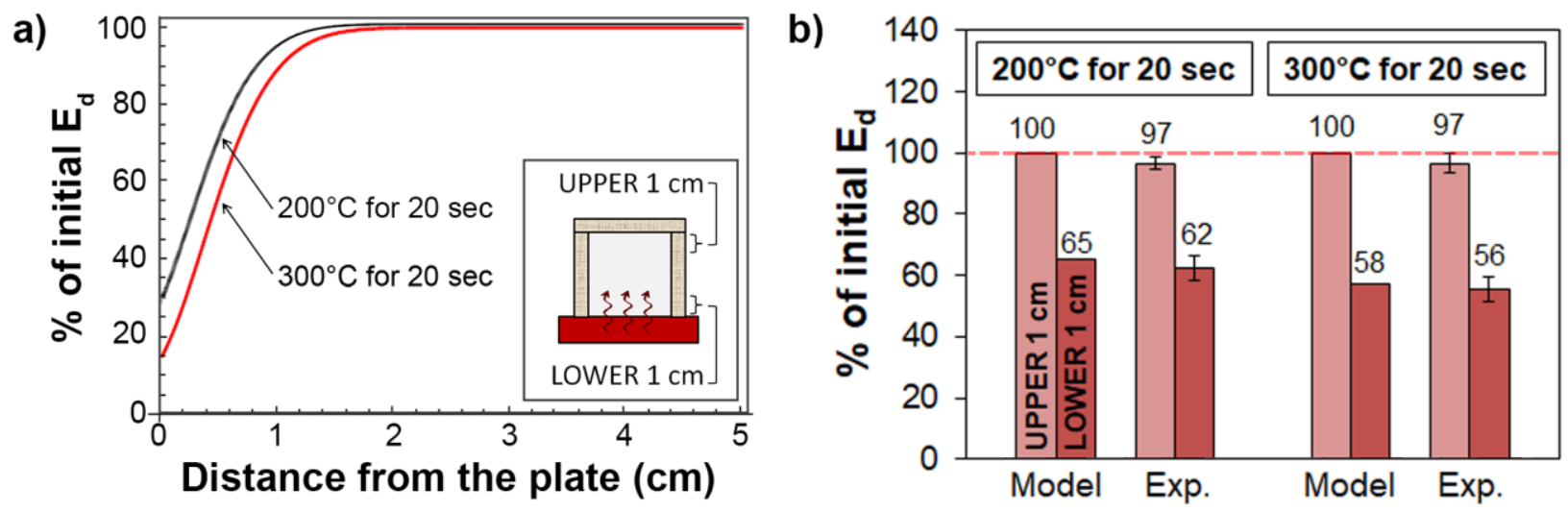

Figure 8. Reduction in dynamic elastic modulus $E_{d}$ after heating at $200{ }^{\circ} \mathrm{C}$ and $300^{\circ} \mathrm{C}$ for 20 seconds: a) profile of $E_{d}$ decrease predicted by the mathematical model as a function of the distance from the heating plate; b) comparison between the average $E_{d}$ decrease predicted in the lower and upper $1 \mathrm{~cm}$ of the sample and that measured experimentally. 
a)

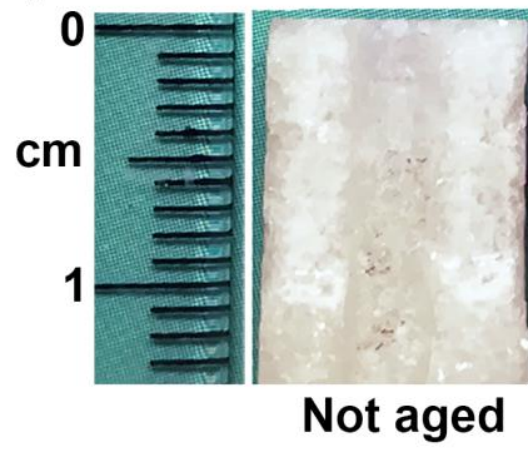

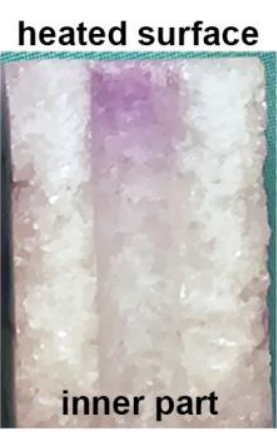

$200{ }^{\circ} \mathrm{C}$ heated surface

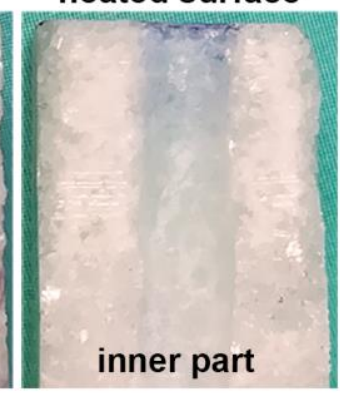

$300{ }^{\circ} \mathrm{C}$ b)

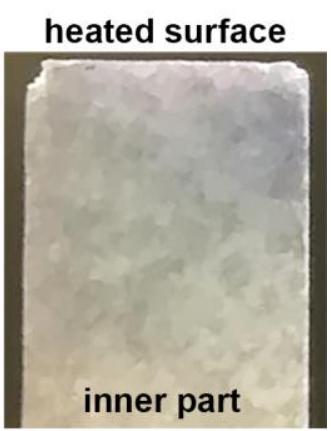

$300{ }^{\circ} \mathrm{C}$

Figure 9. Depth of penetration of the methylene blue solution: a) comparison between fresh marble and marble aged at $200^{\circ}$ and $300{ }^{\circ} \mathrm{C}$ for 20 seconds (the difference in color between the stain in the samples heated at 200 and $300{ }^{\circ} \mathrm{C}$ is due to the different time elapsed between the staining and the observation: a few days in the former case, a few hours in the latter case); b) depth of penetration in the sample heated at $300{ }^{\circ} \mathrm{C}$, as assessed by observing a fracture cross section against the light.

a)

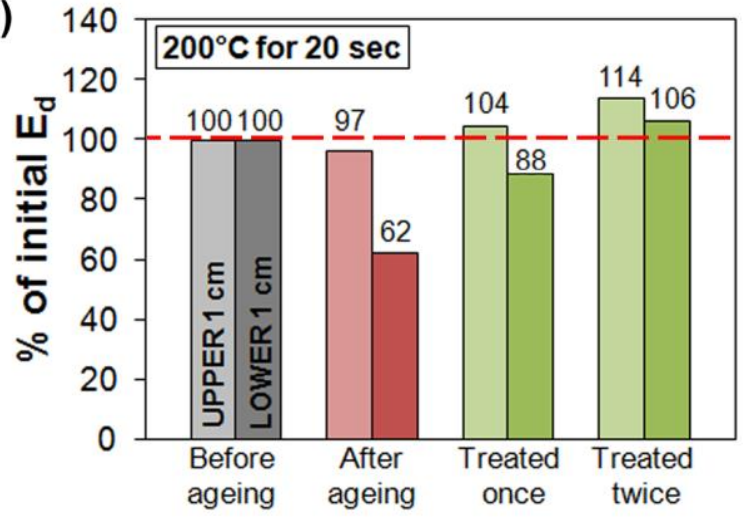

b)

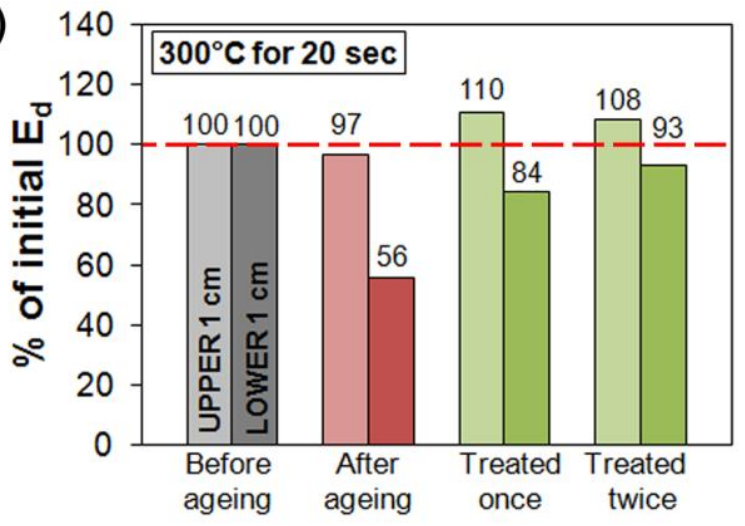

Figure 10. Variations in dynamic elastic modulus $E_{d}$ after accelerated aging by heating at $200{ }^{\circ} \mathrm{C}$ for $20 \mathrm{sec}$ (a) and $300{ }^{\circ} \mathrm{C}$ for $20 \mathrm{sec}$ (b) and after consolidation by the hydroxyapatite-treatment, applied once and twice. 
This is the peer reviewed version of the following article: Sassoni E., Graziani G., Franzoni E., Scherer G.W., New method for controllable accelerated aging of marble: use for testing of consolidants, Journal of the American Ceramic Society, which has been published in final form at DOI: 10.1111/jace.15522. This article may be used for non-commercial purposes in accordance with Wiley Terms and Conditions for Use of Self-Archived Versions.
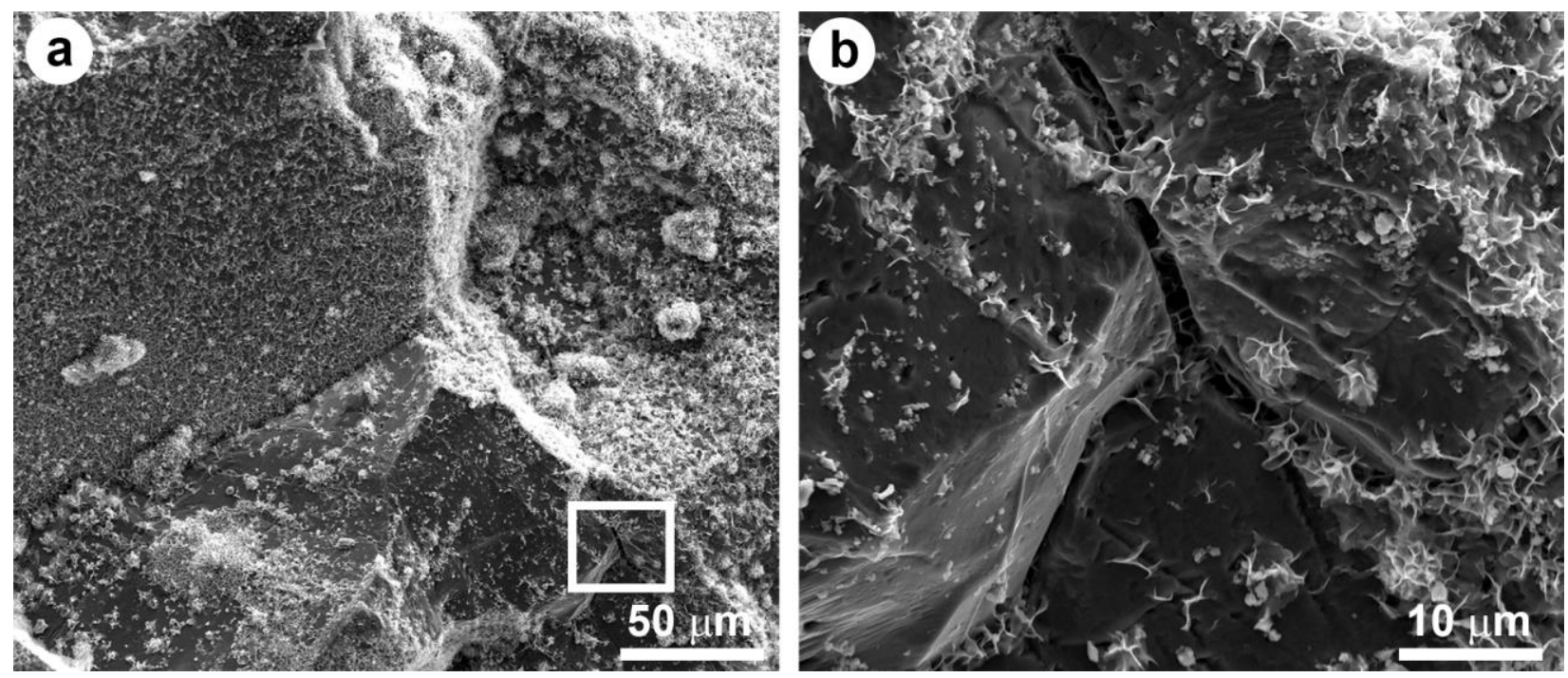

Figure 11. SEM images of a marble sample pre-weathered by heating on a hotplate at $200{ }^{\circ} \mathrm{C}$ for $20 \mathrm{sec}$ and then subjected to the hydroxyapatite-treatment. Magnification: a) $1000 \times$, b) $5000 \times$ (detail of the area identified in a)). 